\title{
A Clinical Evaluation of Circulating MiR-106a and Raf-1 as Breast Cancer Diagnostic and Prognostic Markers
}

\author{
Elham Ahmed Mohmmed ${ }^{1 *}$, Wafaa Ghoneim Shousha ${ }^{2}$, Abeer Salah EL-Saiid ${ }^{3}$, \\ Shimaa Shawki Ramadan ${ }^{2}$
}

\begin{abstract}
Objective: MicroRNAs (MiRNAs) regulate mammalian cell growth, differentiation, and apoptosis by altering the expression of other genes and serve multiple roles in tumorigenesis and progression. Proto-oncogene serine/threonineprotein kinase (RAF-1) functions as a part of the MAPK/ERK signal transduction pathway. The present study aim was to prospectively evaluate MicroRNA 106a (MiR-106a) and RAF-1 as a diagnostic and prognostic factor in early prediction of breast cancer $(\mathrm{BC})$, recurrence and early detection of distant metastasis as well as to analyses the statistical correlation between MiR-106a and RAF-1 levels and clinical-pathological parameters including tumor size, lymph node, histological type and grading. Methods: Sera and plasma of 30 normal women and 50 women with breast carcinoma were assayed for MiR-106a by RT-qPCR as well as levels of Hb, WBCs and platelets count and RAF-1 by solid phase enzyme-linked immunosorbent assay (ELISA). Results: The patients' characteristics, they were classified according to grade into $8 \%$ grade I, $66 \%$ grade II, $22 \%$ grade III and $4 \%$ grade IV. The stages were classified according to the TNM system as stage II was the highest percentage $66 \%$, while the lowest percentage was $10 \%$ for stage I and $24 \%$ for stage III. Also, $\mathrm{Hb} \%$ and RAF-1 levels were significantly decreased in breast cancer patients as compared with healthy control. On the other hand, MiRNA-106a gene expression was non-significantly increased in positive lymph node metastasis patients $(\mathrm{FC}=3.66)$ when compared to patients with negative lymph node metastasis $(\mathrm{FC}=3.51)$. In addition, MiR-106a was significantly up-regulated in breast cancer patients with a fold of change 3.63 when compared to control samples. Conclusion: Expression of MiR-106a gene can be used as a diagnostic and prognostic noninvasive biomarker which can stimulates breast cancer cell invasion and proliferation through downregulation of Raf-1 levels.
\end{abstract}

Keywords: Breast cancer- lymph node- metastasis- MicroRNA-106a- WBCs- platelets and RAF-1

Asian Pac J Cancer Prev, 22 (11), 3513-3520

\section{Introduction}

Breast cancer is the most common cancer among women worldwide, and 70-80 percent of patients with early-stage, non-metastatic disease can be cured (Harbeck et al., 2019). Breast cancer is a personal tragedy for those who are diagnosed. When detected early, it is a highly curable illness, but when detected late, it's almost always fatal. Early diagnosis and access to the best treatment may mean life or death (El Saghir and Anderson, 2012; Milosevic et al., 2018). According to the GLOBOCAN 2020 evaluations of cancer occurrence and mortality formed by the International Agency for Research on Cancer, breast cancer in females has exceeded lung cancer as the most cancer commonly diagnosed, with 2.3 million new estimated cases $(11.7 \%)$, followed by lung (11.4\%) (Sung et al., 2021b). Death rate for female breast cancer was noticeably elevated in transitioning versus transitioned countries (15.0 vs 12.8 per 100,000$)$ (Sung et al., 2021a). Only $25-30 \%$ of women with metastatic breast cancer have a 5-year survival rate (Mondal and Meeran, 2020) and $80 \%$ of women with early breast cancer now surviving 10 years after diagnosis (Chopra and Davies, 2020).

MiRNAs are small, non-coding and highly abundant molecules that have been shown to play critical regulatory roles in a wide range of biological and pathological processes (Lee et al., 1993; Jackson and Standart, 2007; Pawlick et al., 2021). MiRNAs may regulate cellular gene expression at the transcriptional or post-transcriptional level; by suppressing translation of protein coding genes, or cleaving target MiRNAs to induce their degradation, through imperfect pairing with target mRNAs of protein coding genes (Bartel, 2004; Nachtigall and Bovolenta, 2022). Circulating MiRNAs are becoming more widely used as effective biomarkers in a variety of diseases,

${ }^{1}$ Department of Central Labs, National Nutrition Institute, Cairo, Egypt. ${ }^{2}$ Department of Biochemistry, Faculty of Science, Helwan University, Cairo, Egypt. ${ }^{3}$ Department of Clinical and Chemical Pathology, National Cancer Institute, Cairo University, Cairo, Egypt.*For Correspondence: elham.ahmed.mohammed21@science.helwan.edu.eg 
including breast cancer (Jang et al., 2021).

Several studies have explored the differential expression of circulating MiRNAs in BC patients, but very few results are reproducible among laboratories due to population

diversity and lack of standardized protocols about applying MiRNAs in recent clinical practice (Witwer, 2015; Condrat et al., 2020). Aberrant expression of certain MiRNAs has been observed in an array of human cancer types, and MiRNAs are thought to serve important roles in tumorigenesis. Also, a few MiRNAs have been identified as oncogenes or tumor suppressor genes in BC (Hayashita et al., 2005; Ventura et al., 2008; Olive et al., 2010; Chan et al., 2013; Battistella et al., 2015). MiR-106a is expressed in stool samples and in cancer cells of patients with BC with varying degrees (Jung et al., 2012; Schwarzenbach et al., 2014; Kleivi Sahlberg et al., 2015; Mishra et al., 2015; Hamam et al., 2017).

The receptor tyrosine kinase effector, Raf, named for Rapidly Accelerated Fibrosarcoma, was discovered over two decades ago by two groups independently as a retroviral oncogene, v-Raf or v-MIL, possessing a serine/ threonine kinase activity (Baccarini, 2005; Simanshu et al., 2017). Raf-1 Kinase Inhibitor Protein (RKIP) is one of these promising metastasis suppressors, which has various physiologic functions (Hagan et al., 2005; Muslin, 2005; Pottier et al., 2020) . The collective evidence indicates that RKIP regulates the activity and mediates the crosstalk between several important cellular signaling pathways, including the Raf/MAP/extracellular signal regulated kinase (MAPK)/ERK pathway (Galabova-Kovacs et al.,

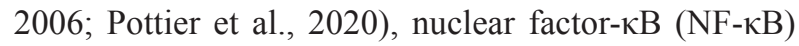
pathway, and G-protein pathway (Kroslak et al., 2001; Shvartsur et al., 2017; El-Fadl et al., 2021).

Breast cancer growth and progression are promoted by aberrant activation of the Raf/MEK/MAPK pathway. Overexpression of the HER-2/Neu tyrosine kinase receptor causes dysregulation of Raf/MEK/MAPK oncogenic signalling, which leads to chemoendocrine resistance, the development of distant metastases, and ultimately a poor prognosis in breast cancer patients (Leontovich et al., 2012). The present study aimed to evaluate the correlation between MiRNA-106a gene expression and levels of $\mathrm{Hb} \%$, WBCs and platelets count as well as tumor marker proteins RAF-1 in a trial to check their early diagnostic and prognostic value which may help to understand their roles in breast cancer.

\section{Materials and Methods}

\section{Patients and Methods}

In this prospective non-randomized study, we enrolled 80 females from the National Cancer Institute, Cairo University. The average age was 26-64 years. Informed consent was obtained from all patients and controls. Group I was composed of 50 breast cancer patients. Group II included 30 healthy controls. On the other hand, the study protocol was approved by the local ethics committee, and informed written consent was obtained from the parents of the patients and volunteers before entering the study.
Inclusion criteria for both groups were females age (26-64 years) when newly diagnosed according to AJCC staging system (7th Edition) classification: Information concerning age, diagnosis and clinical pathology such as tumor size $(\mathrm{T})$, lymph node status $(\mathrm{N})$, grade and hormonal status, for each patient were collected before any treatment through clinical charts (Table 1).

Exclusion criteria included presence of autoimmune disease, acute kidney injury or with unsatisfactory vascular access or any other known condition that would alter growth hormones levels. Moreover, none of our patients had received antibiotics, anti-inflammatory or corticosteroid medications during the study period.

Clinical assessments included complete history taking, past medical and disease history for confirming the appropriateness of the patients to the inclusion criteria.

\section{Blood sampling and Biochemical analyses \\ Sample collection}

The blood samples were collected from Egyptian breast cancer patients and healthy control women during the period 2017 and 2018. Blood samples were gathered in heparinized and non-heparinized tubes. The heparinized tube sample was divided into 2 parts. the first one analyzed for prognostic significance of peripheral blood. The different parameters like $\mathrm{Hb}$ concentration, WBCs and blood platelet count were included in this study. The second part was centrifugated and plasma separated for MiRNA-106a using RT-qPCR. The non-heparinized tubes were allowed to Hemoglobin clot at room temperature for 10-20 $\mathrm{min}$, and sera were then separated by centrifugation (2,000-3,000 rpm, $\left.20 \mathrm{~min}, 25^{\circ} \mathrm{C}\right)$ was stored at $-20^{\circ} \mathrm{C}$ for estimation of serum RAF-1 levels was determined by Enzyme Immunoassay Kit based on the principle of a solid phase enzyme-linked immunosorbent assay (ELISA), purchased from SinoGeneClon Biotech Co., Ltd, Hangzhou, China.

\section{MiRNA-106a analysis using RT-qPCR}

Total RNA was obtained by using QIAamp RNA blood Mini Kit Cat. No. 52304 (Qiagen, Düsseldorf, Germany) following the manufacturer's commands. Total RNA was transcribed reversely using (Thermo Fisher) (200 $\mathrm{U} / \mu \mathrm{L})$, Cat. No. EP0441 following the manufacturer's instructions and complementary DNA (cDNA) synthesis was done in the thermal cycler. Real-time PCR was done using Quantitect SYBR green PCR kit Cat. No. 204141 according to the manufacturer's instructions (Table 2). RNA specific primers for MiR-106a and housekeeping gene (Human GAPDH) are shown in (Table 3). The results of the SYBR green RT-PCR were analyzed as follows: Gene expression levels were calculated using the Stratagene MX3005P instrument, which provided amplification curves and $\mathrm{Ct}$ values.

\section{Statistical analysis}

All the grouped data were statistically evaluated with SPSS $^{\odot}$ Statistics version 27 (IBM ${ }^{\odot}$ Corp., Armonk, NY, USA). c omparison between two groups was performed using an independent sample t-test. While comparison between three groups was done using one way ANOVA 
DOI:10.31557/APJCP.2021.22.11.3513

test. P values of less than 0.05 were considered to indicate statistical significance. All the results were expressed as mean \pm SEM. MiR-106a expression and fold change (FC) were computed using the standard formula (Livak and Schmittgen, 2001). The correlations between numerical variables were estimated by Pearson's correlation coefficient (r) determination.

\section{Results}

This analysis focused on 50 patients with breast carcinoma. The mean age was $49.7 \pm 2.08$ as illustrated in Table 1 . The patients' characteristics, they were classified according to grade into $8 \%$ grade I, $66 \%$ grade II, $22 \%$ grade III and $4 \%$ grade IV. The stages were classified according to the TNM system as stage II was the highest percentage $66 \%$, While the lowest percentage was $10 \%$ for

Table 1. Main Clinical-Pathological Characteristics of 50 Breast Cancer Patients

\begin{tabular}{|c|c|c|}
\hline Parameters N \% & $\mathrm{N}$ & $\%$ \\
\hline Age mean $49.7 \pm 2.08$ & 50 & 100 \\
\hline \multicolumn{3}{|l|}{ Tumor size } \\
\hline $\mathrm{T} 1<2$ & 8 & 16 \\
\hline T2 $2-5$ & 37 & 74 \\
\hline $\mathrm{T} 3>5$ & 5 & 10 \\
\hline \multicolumn{3}{|l|}{ Auxiliary lymph node } \\
\hline Positive & 42 & 84 \\
\hline Negative & 8 & 16 \\
\hline \multicolumn{3}{|l|}{ Pathological grade } \\
\hline Grade I & 4 & 8 \\
\hline Grade II & 33 & 66 \\
\hline Grade III & 11 & 22 \\
\hline Grade IV & 2 & 4 \\
\hline \multicolumn{3}{|l|}{ Clinical stage } \\
\hline Stage 1 & 5 & 10 \\
\hline Stage 2 & 33 & 66 \\
\hline Stage 3 & 12 & 24 \\
\hline \multicolumn{3}{|l|}{ Pathological type } \\
\hline IDC & 40 & 80 \\
\hline ILC & 5 & 10 \\
\hline ICC & 4 & 8 \\
\hline \multicolumn{3}{|l|}{ Estrogen receptor } \\
\hline Positive & 20 & 40 \\
\hline Negative & 30 & 60 \\
\hline \multicolumn{3}{|l|}{ Progesterone receptor } \\
\hline Positive & 17 & 34 \\
\hline Negative & 33 & 66 \\
\hline \multicolumn{3}{|l|}{ HER-2 } \\
\hline Positive & 13 & 26 \\
\hline Negative & 37 & 74 \\
\hline \multicolumn{3}{|l|}{ Family History } \\
\hline Positive & 12 & 24 \\
\hline Negative & 38 & 76 \\
\hline
\end{tabular}

Table 2. SYBR Green Real-Time PCR Cycling Conditions

\begin{tabular}{lllll}
\hline Gene & \multicolumn{2}{c}{ MiR-106a } & GAPDH \\
& Time & Temp & Time & Temp \\
& & $\left({ }^{\circ} \mathrm{C}\right)$ & & $\left({ }^{\circ} \mathrm{C}\right)$ \\
\hline Reverse transcription & $30 \mathrm{~min}$ & $50^{\circ} \mathrm{C}$ & $30 \mathrm{~min}$ & $50^{\circ} \mathrm{C}$ \\
Primary denaturation & $5 \mathrm{~min}$. & $94^{\circ} \mathrm{C}$ & $5 \mathrm{~min}$. & $94^{\circ} \mathrm{C}$ \\
Amplifcation (40 cycles) & & & & \\
Secondary denaturation & $15 \mathrm{sec}$ & $94{ }^{\circ} \mathrm{C}$ & $15 \mathrm{sec}$ & $94{ }^{\circ} \mathrm{C}$ \\
Annealing (optics on) & $30 \mathrm{sec}$. & $58{ }^{\circ} \mathrm{C}$ & $30 \mathrm{sec}$. & $58{ }^{\circ} \mathrm{C}$ \\
Extension & $30 \mathrm{sec}$. & $72{ }^{\circ} \mathrm{C}$ & $30 \mathrm{sec}$. & $72{ }^{\circ} \mathrm{C}$ \\
Dissociation curve (1 cycle) & & & \\
Secondary denaturation & $1 \mathrm{~min}$. & $94{ }^{\circ} \mathrm{C}$ & $1 \mathrm{~min}$. & $94{ }^{\circ} \mathrm{C}$ \\
Annealing & $1 \mathrm{~min}$. & $58{ }^{\circ} \mathrm{C}$ & $1 \mathrm{~min}$. & $58{ }^{\circ} \mathrm{C}$ \\
Final denaturation & $1 \mathrm{~min}$. & $94{ }^{\circ} \mathrm{C}$ & $1 \mathrm{~min}$. & $94{ }^{\circ} \mathrm{C}$ \\
\hline
\end{tabular}

stage I and $24 \%$ for stage III. The classification according to tumor size was $>5 \mathrm{~cm}$ in $10 \%$ of patients, $<2 \mathrm{~cm}$ in $16 \%$ and, between $2-5 \mathrm{~cm}$ in $74 \%$.

$\mathrm{Hb}$ level was noted in breast cancer patients. Hb count was found to be in the range of 9-14 gm/dl. The mean of $\mathrm{Hb}$ level was significantly decreased $(9.58 \pm 0.19)$ as compared to the mean value of $\mathrm{Hb}$ level in healthy control (12.81 \pm 0.26$)(\mathrm{P}=0.000)$. The level of Hb falls, and this may cause the risk of anemia in the breast cancer patients (Table 4). The mean of WBCs count level was significantly increased $(6.64 \pm 0.11) \times 10^{3} / \mathrm{mm}^{3}$ as compared to the mean value of WBCs in healthy control $(5.19 \pm 0.32) \times 10^{3} / \mathrm{mm}^{3}$ $(\mathrm{P}=0.000)$. The platelet count of peripheral blood has an important diagnostic significance. The majority of patients were found with $(392.90 \pm 8.05) \times 10^{3} / \mathrm{mm}^{3}$ as compared to the mean value of Platelet count in healthy control $(291.78 \pm 0.20) \times 10^{3} / \mathrm{mm}^{3}(\mathrm{P}=0.000)$ (Table 4).

Table 4 showed the serum RAF-1 levels of breast

Table 3. RNA Specifc Primers for MiR-106a Gene and Housekeeping Gene (Human GAPDH)

\begin{tabular}{lll}
\hline Gene & Primer sequence (5'-3') & Reference \\
\hline Human & CTCTGATTTGGTCGTATTGGG & (Li et al., 2014) \\
GAPDH & TGGAAGATGGTGATGGGATT & \\
MiR-106a & ATCCAGTGCGTGTCGTG & \\
& TGCTAAAAGTGCTTACAGTG & \\
& GTG CAG GGT CCG AGG T & \\
\hline
\end{tabular}

Table 4. The Levels of HB, Platelets, WBCs, RAF-1 and MiR-106a delta $\mathrm{Ct}$ of Breast Cancer Patients and Healthy Control

\begin{tabular}{lccc}
\hline Parameter & Patients & $\begin{array}{c}\text { Health } \\
\text { control }\end{array}$ & P-value \\
& Mean $\pm \mathrm{SE}$ & Mean $\pm \mathrm{SE}$ & \\
\hline $\mathrm{HB}(\mathrm{gm} / \mathrm{dl})$ & $9.58 \pm 0.19$ & $12.81 \pm 0.26$ & $0.000^{* *}$ \\
Platelets $\left(\mathrm{x} 10^{3} / \mathrm{mm}^{3}\right)$ & $392.90 \pm 8.05$ & $291.78 \pm 0.20$ & $0.000^{* *}$ \\
WBCs $\left(\mathrm{x} 10^{3} / \mathrm{mm}^{3}\right)$ & $6.64 \pm 0.11$ & $5.19 \pm 0.32$ & $0.000^{* *}$ \\
RAF-1 $(\mathrm{pg} / \mathrm{ml})$ & $61.50 \pm 1.10$ & $68.51 \pm 2.81$ & $0.01 *^{*}$ \\
MiR-106a delta Ct & $-1.2050 \pm 0.11511$ & $0.53 \pm 0.41$ & $0.000^{* *}$ \\
\hline Data were expressed as mean \pm standard Error. *, is significant; **, is \\
highly significant.
\end{tabular}


Table 5. Fold Change Data Analysis of Tested Circulating MiR-106a in the Serum of Cancer Patients

\begin{tabular}{|c|c|c|c|c|c|}
\hline & GAPDH Ct & MiR-106a Ct & $\Delta \mathrm{Ct}$ & $\Delta \Delta \mathrm{Ct}$ & $\mathrm{FC}$ \\
\hline \multicolumn{6}{|c|}{ Compared to the healthy control group } \\
\hline Control & 27.29 & 27.82 & 0.53 & 0 & 1.00 \\
\hline Patients & 25.78 & 24.57 & -1.20 & -1.73 & 3.63 \\
\hline \multicolumn{6}{|c|}{ Pathological grade } \\
\hline Grade I & 23.30 & 22.32 & -0.99 & -1.51 & 2.85 \\
\hline Grade II & 26.04 & 24.79 & -1.24 & -1.77 & 3.80 \\
\hline Grade III & 26.03 & 24.90 & -1.13 & -1.65 & 3.34 \\
\hline Grade IV & 23.86 & 22.45 & -1.41 & -1.94 & 3.83 \\
\hline \multicolumn{6}{|c|}{ Clinical Stage } \\
\hline Stage I & 24.76 & 23.52 & -1.25 & -1.77 & 3.73 \\
\hline Stage II & 25.93 & 24.69 & -1.24 & -1.77 & 3.73 \\
\hline Stage III & 25.77 & 24.70 & -1.08 & -1.60 & 3.32 \\
\hline \multicolumn{6}{|c|}{ Pathological type } \\
\hline IDC & 25.89 & 24.62 & -1.27 & -1.80 & 3.80 \\
\hline ILC & 25.87 & 24.67 & -1.21 & -1.73 & 3.47 \\
\hline ICC & 23.30 & 22.32 & 0.99 & -1.51 & 2.85 \\
\hline \multicolumn{6}{|c|}{ Auxiliary lymph node } \\
\hline Positive & 25.98 & 24.78 & 1.20 & -1.73 & 3.66 \\
\hline Negative & 24.75 & 23.59 & -1.20 & -1.73 & 3.51 \\
\hline \multicolumn{6}{|l|}{ Tumor size } \\
\hline $\mathrm{T} 1<2$ & 25.38 & 24.12 & -1.26 & -1.79 & 3.80 \\
\hline $\mathrm{T} 22-5$ & 25.92 & 24.76 & -1.16 & -1.69 & 3.54 \\
\hline $\mathrm{T} 3>5$ & 25.40 & 23.98 & -1.43 & -1.95 & 4.05 \\
\hline \multicolumn{6}{|c|}{ Estrogen receptor } \\
\hline Negative & 25.82 & 24.50 & -1.32 & -1.84 & 3.95 \\
\hline Positive & 25.72 & 24.68 & -1.04 & -1.57 & 3.16 \\
\hline \multicolumn{6}{|c|}{ Progesterone receptor } \\
\hline Negative & 25.67 & 24.38 & -1.30 & -1.82 & 3.87 \\
\hline Positive & 25.99 & 24.96 & -1.02 & -1.55 & 3.15 \\
\hline \multicolumn{6}{|l|}{ HER-2 } \\
\hline Positive & 25.42 & 24.16 & -1.26 & -1.78 & 3.83 \\
\hline Negative & 25.90 & 24.72 & -1.19 & -1.71 & 3.56 \\
\hline \multicolumn{6}{|c|}{ Family History } \\
\hline Yes & 26.40 & 24.99 & -1.41 & -1.94 & 4.16 \\
\hline No & 25.59 & 24.44 & -1.14 & -1.67 & 3.47 \\
\hline
\end{tabular}

cancer patients and health control females. RAF-1 levels were significantly decreased in each patient $(61.50 \pm 1.10$ $\mathrm{pg} / \mathrm{ml})$ as compared to mean value of RAF-1 in healthy control $(68.51 \pm 2.81 \mathrm{pg} / \mathrm{ml})(\mathrm{P}=0.011)$. In other hand Raf-1 serum level was significantly increased in patients have estrogen and progesterone receptors as compared to patients with no receptors ( $\mathrm{p}=.016 ; 0.174$ respectively) as in Table 4.

Identification of Deregulated MiRNA by the $\triangle \Delta C t$ Method Input data from the Gene Globe data analysis tool were computed using the standard delta-delta $\mathrm{Ct}$ method $(\Delta \Delta \mathrm{Ct})$ with GAPDH $\mathrm{Ct}$ as references. Fold change was calculated, and the homogeneity of data was visualized. Up- or downregulation of MiRNA was confirmed in 100\% of analyzed samples when compared to the Gene Globe final experiment (Table 5). The $\Delta \Delta \mathrm{Ct}$ method identified MiR-106a delta Ct was significantly decreased in breast cancer patients $(-1.2050 \pm 0.11511)$ when compared to control samples $(0.53 \pm 0.41)(\mathrm{P}=0.000)$ as in Table 4 . Also, it was observed that, MiR-106a gene was highly expressed in breast cancer patients $(\mathrm{FC}=3.63)$ as in table 3 which showed that the relative expression of MiR-106a gene in $\mathrm{BC}$ patients was significantly increased compared to healthy control females.

Also, data in Table 6 illustrated that, the expression of MiR-106a gene was increased in grade IV $(\mathrm{FC}=3.83)$ compared to grade III $(\mathrm{FC}=3.34)$ but the increase was not statistically significant. In addition, the expression of MiR-106a gene was decreased in stage III $(\mathrm{FC}=3.32)$ 


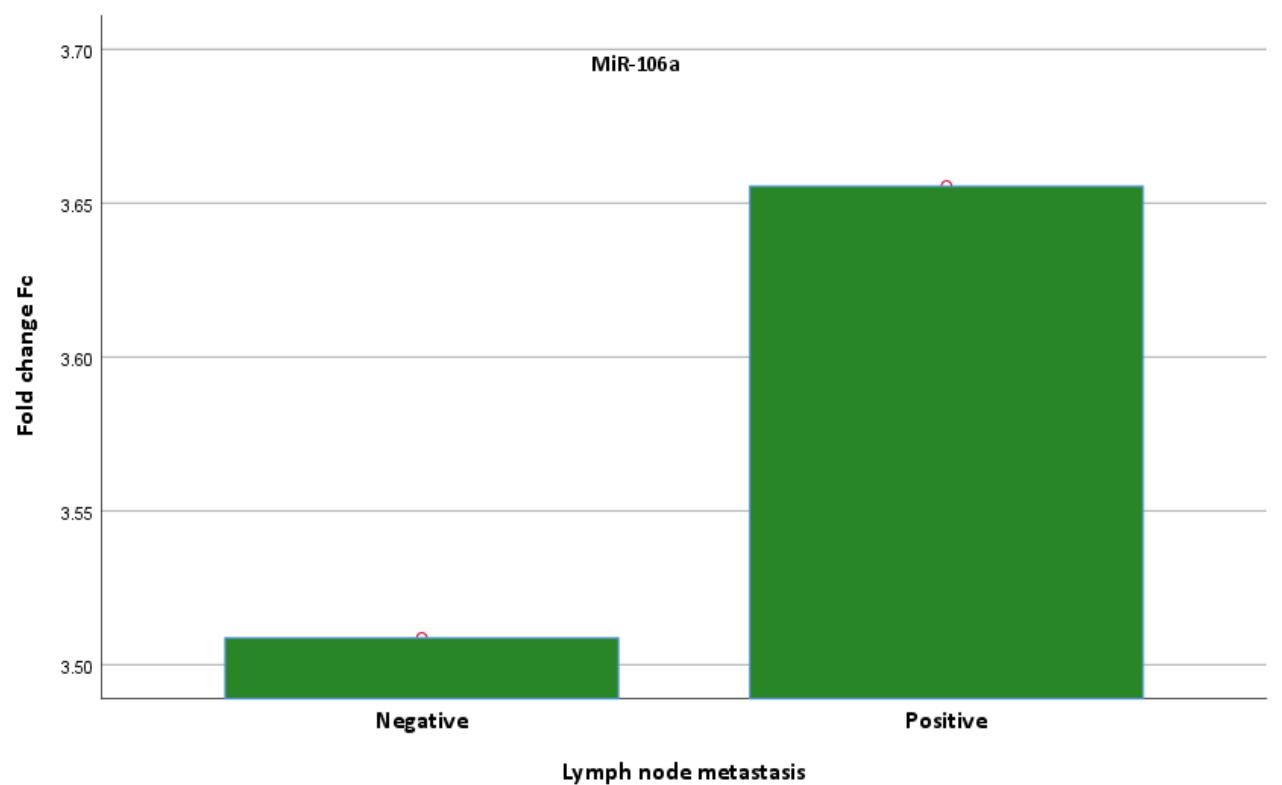

Figure 1. Graph of Fold Change of MiR-106a for Negative and Positive Lymph Node Metastasis

compared to grade II $(\mathrm{FC}=3.73)$ but the decrease wasn't statistically significant. The data also clarified that, MiR106a gene expression in positive lymph node metastasis patients $(\mathrm{FC}=3.66)$ was higher than that of the negative lymph node metastasis patients $(\mathrm{FC}=3.52)$ but the increase was regarded as statistically non-significant as illustrated in Figure 1.

Table 7 showed the correlation between MiR-106a $\mathrm{FC}$ and $\mathrm{Hb} \%$, WBC, Platelets and RAF-1 in the breast cancer patients. The present results indicated that a nonsignificant negative correlation was observed between MiR-106a and $\mathrm{Hb} \%(\mathrm{r}=-0.059, \mathrm{p}<0.758)$.

In addition, our results showed that a non-significant negative correlation was observed between MiR-106a and WBCs $(\mathrm{r}=-0.057, \mathrm{p}<0.763)$. on the other hand, a non-significant positive correlation was observed between MiR-106a and Platelets ( $\mathrm{r}=+0.010, \mathrm{p}<0.959)$.

Also, a non-significant negative correlation between

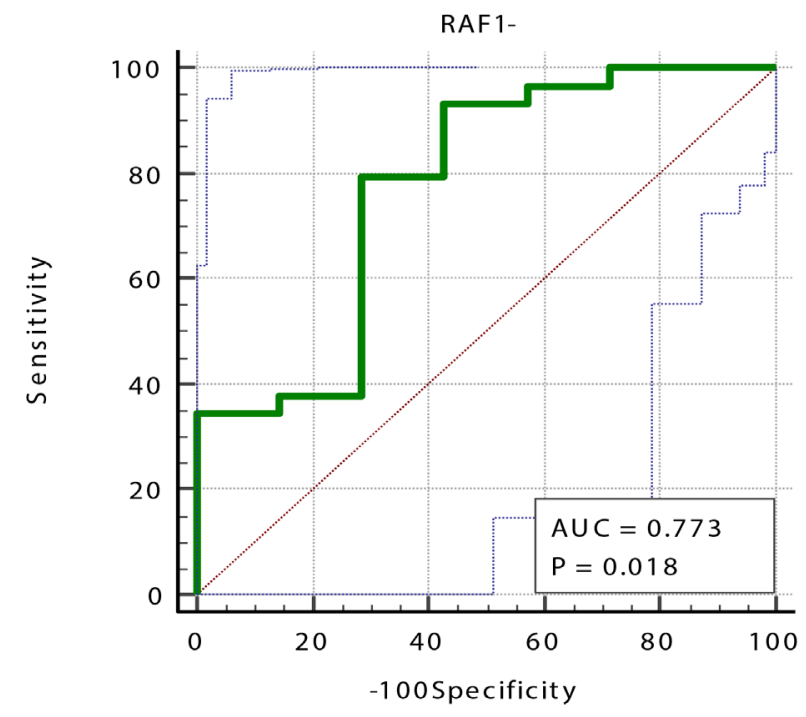

Figure 2. ROC Curve of RAF-1 in BC Patients Compared to Healthy Control
MiR-106a FC and RAF-1 was noted $(r=-0.191, p$ $<0.322$ ). Table 8 and Figures 2 and 3, showed that MiR106a FC showed a very high diagnostic value (AUC = 0.947 , specificity $=83.33 \%$, sensitivity $=100 \%$, p-value $=0.0001$ ) in opposite to RAF-1 which showed a very low diagnostic value $(\mathrm{AUC}=0.773$, specificity $=71.43 \%$, sensitivity $=79.31 \%$, p-value $=0.081)$.

\section{Discussion}

In women, breast cancer is the leading cause of cancer-related death. Breast cancer-related mortality is mainly caused by recurrence of the primary tumor and metastasis to distant body parts (Mondal and Meeran, 2020). Gene expression variations have resulted in the emergence of recent technical advances in cancer diagnosis, allowing for a better understanding of tumor behavior. It has improved not only the prognosis, but also

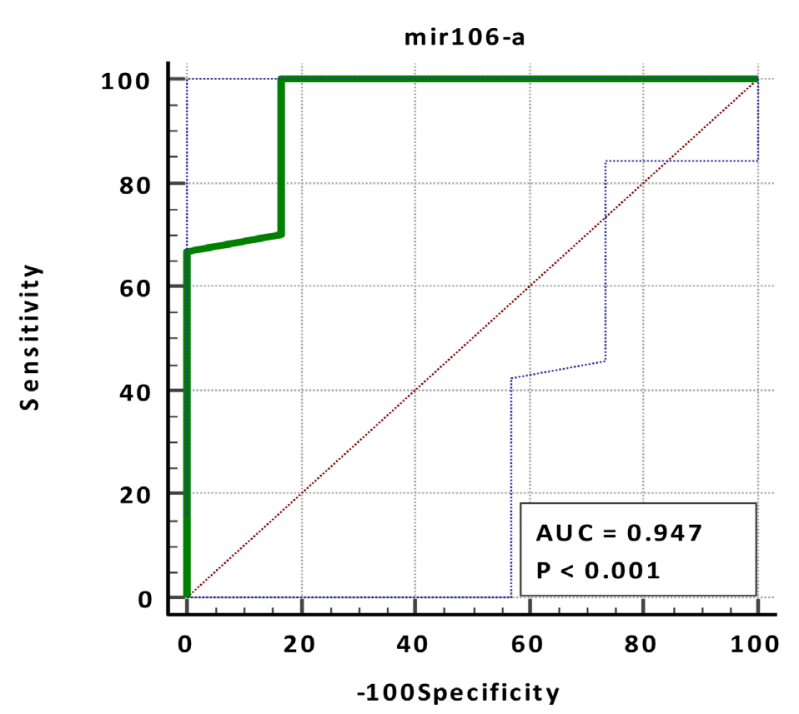

Figure 3. ROC Curve of MiR-106a in BC Patients Compared to Healthy Control 
Table 6. Correlation between MiR-106a and RAF-1 with Clinical-Pathological Data of Breast Cancer Patients

\begin{tabular}{|c|c|c|}
\hline & RAF-1 & MiR-106a FC \\
\hline \multicolumn{3}{|c|}{ Pathological grade } \\
\hline I & $58.15 \pm 6.97$ & $2.85 \pm 0.11$ \\
\hline II & $61.90 \pm 1.29$ & $3.80 \pm 0.39$ \\
\hline III & $62.07 \pm 2.59$ & $3.34 \pm 0.49$ \\
\hline IV & $56.75 \pm 0$ & $3.83 \pm 0$ \\
\hline P-value & 0.719 & 0.817 \\
\hline \multicolumn{3}{|c|}{ Clinical Stage } \\
\hline I & $64.94 \pm 2.54$ & $3.73 \pm 3.32$ \\
\hline II & $61.32 \pm 1.47$ & $3.73 \pm 0.36$ \\
\hline III & $61.02 \pm 1.66$ & $3.32 \pm 0.52$ \\
\hline P-value & 0.705 & 0.839 \\
\hline \multicolumn{3}{|c|}{ Pathological type } \\
\hline IDC & $61.94 \pm 1.18$ & $3.81 \pm 0.33$ \\
\hline ILC & $59.91 \pm 4.85$ & $3.47 \pm 0.76$ \\
\hline $\mathrm{ICC}$ & $58.15 \pm 6.97$ & $3.47 \pm 0.11$ \\
\hline P-value & 0.638 & 0.683 \\
\hline \multicolumn{3}{|c|}{ Auxiliary lymph node } \\
\hline Positive & $61.88 \pm 1.15$ & $3.66 \pm 0.32$ \\
\hline Negative & $59.098 \pm 3.63$ & $3.51 \pm 0.62$ \\
\hline P-value & 0.392 & 0.85 \\
\hline \multicolumn{3}{|l|}{ Tumor size } \\
\hline $\mathrm{T} 1<2$ & $63.07 \pm 3.14$ & $3.80 \pm 0.79$ \\
\hline T2 $2-5$ & $61.21 \pm 1.36$ & $3.47 \pm 0.35$ \\
\hline $\mathrm{T} 3>5$ & $59.89 \pm 2.82$ & $4.06 \pm 0.79$ \\
\hline P-value & 0.781 & 0.795 \\
\hline \multicolumn{3}{|c|}{ Estrogen receptor } \\
\hline Negative & $63.66 \pm 1.42$ & $3.95 \pm 0.41$ \\
\hline Positive & $58.44 \pm 1.35$ & $3.17 \pm 0.32$ \\
\hline P-value & $0.016^{*}$ & 0.174 \\
\hline \multicolumn{3}{|c|}{ Progesterone receptor } \\
\hline Positive & $58.07 \pm 1.61$ & $3.15 \pm 0.38$ \\
\hline Negative & $63.30 \pm 1.23$ & $3.87 \pm 0.37$ \\
\hline P-value & $0.021 *$ & 0.235 \\
\hline \multicolumn{3}{|l|}{ HER-2 } \\
\hline Positive & $61.49 \pm 1.70$ & $3.83 \pm 0.70$ \\
\hline Negative & $61.50 \pm 1.40$ & $3.56 \pm 0.30$ \\
\hline P-value & 0.998 & 0.681 \\
\hline \multicolumn{3}{|c|}{ Family History } \\
\hline Yes & $56.36 \pm 1.38$ & $4.17 \pm 0.73$ \\
\hline No & $63.13 \pm 1.19$ & $3.47 \pm 0.30$ \\
\hline P-value & $0.006^{* *}$ & 0.304 \\
\hline
\end{tabular}

Data were expressed as mean \pm standard Error. *, is significant $* *$, is highly significant.

Table 8. The Sensitivity, Specificity, Cut off, and AUC (Area under Curve) for MiR-106a FC and RAF-1 in Breast Cancer Patients

\begin{tabular}{lccccccc}
\hline Parameters & AUC & P-value & \multicolumn{2}{c}{$95 \%$ Confidence Interval } & Cut off & Sensitivity & Specificity \\
& & & Lower Bound & Upper Bound & Value & & \\
\hline MiR-106a Fold change & 0.947 & $<0.0001$ & 0.817 & 0.994 & $>1.45$ & 100 & 83.33 \\
RAF-1 & 0.773 & 0.018 & 0.604 & 0.896 & $\leq 66.08$ & 79.31 & 71.43 \\
\hline
\end{tabular}

Table 7. Correlation between MiR-106a FC and $\mathrm{Hb} \%$, WBC, Platelets \& RAF-1 in the Breast Cancer Patients

\begin{tabular}{lccccc}
\hline & & HB & WBC & Platelets & RAF-1 \\
\hline WBC & r & 0.107 & & & \\
Platelets & $\mathrm{p}$ & 0.573 & & & \\
& $\mathrm{r}$ & 0.206 & -0.323 & & \\
RAF-1 & $\mathrm{p}$ & 0.274 & 0.082 & & \\
& $\mathrm{r}$ & 0.131 & -0.155 & -0.044 & \\
MiR-106a FC & $\mathrm{r}$ & -0.059 & -0.057 & 0.010 & -0.191 \\
& $\mathrm{p}$ & 0.758 & 0.763 & 0.959 & 0.322 \\
\hline
\end{tabular}

r, correlation coefficient; P-value, probability value; *, is significant; **, is highly significant.

the early detection and treatment of cancer (Latha et al., 2020). BC has been shown to have abnormal MiRNA cluster expression, which can be both pro-tumorigenic and anti-tumorigenic. So, the use of circulating MiRNAs in breast cancer diagnosis is less invasive and efficient than traditional tissue biopsy(Yoshikawa et al., 2018; Swellam et al., 2019). The role of MiR-106a in the controversial. Several studies have shown that MiR-106a can act as a tumor suppressor or oncogene in various cancer types, depending on the cellular context (Yang et al., 2011; Kim et al., 2012). In this study, we focused on MiR-106a, which is located on chromosome $\mathrm{X}$ and has received little attention in $\mathrm{BC}$ despite the strong correlation between sex and the incidence of $\mathrm{BC}$ well as its correlation with RAF-1 levels (Li et al., 2018). Our study demonstrated that the overexpression of MiR-106a induced proliferation and decreased apoptosis in cells could be by inhibition of RAF-1 gene expression. It's approved that MiR-106a overexpression stimulates breast cancer cell invasion and proliferation through upregulation of Bcl-2, ABCG2, and P53, and downregulation of Bax and RUNX3. (You et al., 2019). At the same time, studies showed that Proto-oncogene serine/threonineprotein kinase (Raf-1) functions as a part of the MAPK/ ERK signal transduction pathway. Once activated, Raf-1 phosphorylates and activates MEK1 and MEK2 protein kinases and then, in turn, phosphorylates and activates the serine/threonine-specific protein kinases ERK1 and ERK2 to control expression of various genes (such as Bcl-2 and P-glycoprotein) in the regulation of cell cycle, cell migration, apoptosis and differentiation (Hoyle et al., 2000; Cekanova et al., 2007).

In previous assessed breast tumors, corresponding serum from patients showed that MiR-106a was significantly overexpressed in both breast tumors and corresponding serum samples(Li et al., 2018; Zhang development of tumor malignancy is complex and 
et al., 2021). The expression was higher in negative progesterone receptor versus positive patients, and also in negative estrogen receptor versus positive ER patients (Wang et al., 2010). The result of our study showed that, MiR-106a gene was elevated in negative progesterone receptor as compared to positive patient $(\mathrm{Fc}=3.87$ and 3.15, respectively) and MiR-106a gene was raised in negative estrogen receptor as compared to positive patient $(\mathrm{Fc}=3.95$ and 3.16, respectively).

Moreover MiR-106a slows monocyte and then macrophage growth (Fontana et al., 2007). That could decrease the primary clearing reactions to altered cells and may increase the prevalence of breast cancer. It is approved that, in the intrinsic pathway for apoptosis initiation, caspase 6 is the direct activator of caspase 8 (Cowling and Downward, 2002). A reduction in caspase 6 and caspase 8 expression induced by elevated MiR-106a would be expected to reduce apoptosis, resulting in an increase in cell number (Vakkala et al., 1999).

In conclusion, the results of the current study demonstrated that MiR-106a functions as an oncogene and increases in BC cancers. The MiR-106a clearly targets genes involved in tumorigenesis, proliferation, invasion, migration, and metastases. So, the MiR-106a gene may serve as a potential genetic noninvasive biomarker in breast cancer patients, through regulating RAF-1 expression. However, in vivo studies of related cytokines and inflammatory mediators are warranted to validate these findings.

\section{Author Contribution Statement}

All the authors contributed equally to this work.

\section{Acknowledgments}

We thank all the staff of the central laboratories in the National Cancer Institute for their excellent technical assistance. This study was approved by ethics committee of National Cancer Institute, Cairo University, Egypt (No. 201716064.4).

\section{Ethical approval}

All procedures performed in the study involving human participants were in accordance with the ethical standards of the ethics committee of National Cancer Institute, Cairo University, Egypt (No. 201716064.4).

\section{Conflict of interest}

The authors declare that they have no conflict of interest.

\section{References}

Baccarini M (2005). Second nature: biological functions of the Raf-1 "kinase". FEBS Lett, 579, 3271-7.

Bartel DP (2004). MicroRNAs: genomics, biogenesis, mechanism, and function. Cell, 116, 281-97.

Battistella M, Romero M, Castro-Vega LJ, et al (2015). The high expression of the microRNA 17-92 cluster and its paralogs, and the downregulation of the target gene PTEN, is associated with primary cutaneous B-Cell lymphoma progression. J Invest Dermatol, 135, 1659-67.

Cekanova M, Majidy M, Masi T, et al (2007). Overexpressed Raf-1 and phosphorylated cyclic adenosine 3'-5'-monophosphatate response element-binding protein are early markers for lung adenocarcinoma. Cancer, 109, 1164-73.

Chan M, Liaw CS, Ji SM, et al (2013). Identification of circulating microRNA signatures for breast cancer detection. Clin Cancer Res, 19, 4477-87.

Chopra S, Davies EL (2020). Breast cancer. Medicine, 48, 113-8.

Condrat CE, Thompson DC, Barbu MG, et al (2020). miRNAs as biomarkers in disease: Latest Findings Regarding Their Role in Diagnosis and Prognosis. Cells, 9, 276.

Cowling V, Downward J (2002). Caspase-6 is the direct activator of caspase- 8 in the cytochrome c-induced apoptosis pathway: absolute requirement for removal of caspase-6 prodomain. Cell Death Differ, 9, 1046-56.

El-Fadl HMA, Hagag NM, El-Shafei RA, et al (2021). Effective targeting of Raf- 1 and its associated autophagy by novel extracted peptide for treating breast cancer. Cells, 11.

El Saghir NS, Anderson BO (2012). Breast cancer early detection and resources: Where in the world do we start?. Breast $J$, 21, 423-5.

Fontana L, Pelosi E, Greco P, et al (2007). MicroRNAs 17-5p-20a-106a control monocytopoiesis through AML1 targeting and M-CSF receptor upregulation. Nat Cell Biol, 9, 775-87.

Galabova-Kovacs G, Kolbus A, Matzen D, et al (2006). ERK and beyond: insights from B-Raf and Raf-1 conditional knockouts. Cell Cycle, 5, 1514-8.

Hagan S, Al-Mulla F, Mallon E, et al (2005). Reduction of Raf1 kinase inhibitor protein expression correlates with breast cancer metastasis. Clin Cancer Res, 11, 7392-7.

Hamam R, Hamam D, Alsaleh KA, et al (2017). Circulating microRNAs in breast cancer: novel diagnostic and prognostic biomarkers. Cell Death Dis, 8, e3045-e.

Harbeck N, Penault-Llorca F, Cortes J, et al (2019). Breast cancer. Nat Rev Dis Primers, 5, 66.

Hayashita Y, Osada H, Tatematsu Y, et al (2005). A polycistronic microRNA cluster, miR-17-92, is overexpressed in human lung cancers and enhances cell proliferation. Cancer Res, 65, 9628-32.

Hoyle PE, Moye PW, Steelman LS, et al (2000). Differential abilities of the Raf family of protein kinases to abrogate cytokine dependency and prevent apoptosis in murine hematopoietic cells by a MEK1-dependent mechanism. Leukemia, 14, 642-56.

Jackson RJ, Standart N (2007). How do microRNAs regulate gene expression?. Sci STKE, 2007, re1.

Jang JY, Kim YS, Kang KN, et al (2021). Multiple microRNAs as biomarkers for early breast cancer diagnosis. Mol Clin Oncol, 14, 31-.

Jung EJ, Santarpia L, Kim J, et al (2012). Plasma microRNA 210 levels correlate with sensitivity to trastuzumab and tumor presence in breast cancer patients. Cancer, 118, 2603-14.

Kim K, Chadalapaka G, Lee SO, et al (2012). Identification of oncogenic microRNA-17-92/ZBTB4/specificity protein axis in breast cancer. Oncogene, 31, 1034-44.

Kleivi Sahlberg K, Bottai G, Naume B, et al (2015). A serum microRNA signature predicts tumor relapse and survival in triple-negative breast cancer patients. Clin Cancer Res, 21, 1207-14.

Kroslak T, Koch T, Kahl E, et al (2001). Human phosphatidylethanolamine-binding protein facilitates heterotrimeric $\mathrm{G}$ protein-dependent signaling. J Biol Chem, 276, 39772-8.

Latha NR, Rajan A, Nadhan R, et al (2020). Gene expression 
signatures: A tool for analysis of breast cancer prognosis and therapy. Crit Rev Oncol Hematol, 151, 102964.

Lee RC, Feinbaum RL, Ambros V (1993). The C. elegans heterochronic gene lin-4 encodes small RNAs with antisense complementarity to lin-14. Cell, 75, 843-54.

Leontovich AA, Zhang S, Quatraro C, et al (2012). Raf-1 oncogenic signaling is linked to activation of mesenchymal to epithelial transition pathway in metastatic breast cancer cells. Int J Oncol, 40, 1858-64.

Li M, Zhou Y, Xia T, et al (2018). Circulating microRNAs from the miR-106a-363 cluster on chromosome $\mathrm{X}$ as novel diagnostic biomarkers for breast cancer. Breast Cancer Res Treat, 170, 257-70.

Li P, Xu Q, Zhang D, et al (2014). Upregulated miR-106a plays an oncogenic role in pancreatic cancer. FEBS Lett, 588, 705-12.

Livak KJ, Schmittgen TD (2001). Analysis of relative gene expression data using real-time quantitative PCR and the 2(-Delta Delta C(T)) Method. Methods, 25, 402-8.

Milosevic M, Jankovic D, Milenkovic A, et al (2018). Early diagnosis and detection of breast cancer. Technol Health Care, 26, 729-59.

Mishra S, Srivastava AK, Suman S, et al (2015). Circulating miRNAs revealed as surrogate molecular signatures for the early detection of breast cancer. Cancer Lett, 369, 67-75.

Mondal P, Meeran SM (2020). Long non-coding RNAs in breast cancer metastasis. Non-Coding RNA Res, 5, 208-18.

Muslin AJ (2005). Role of raf proteins in cardiac hypertrophy and cardiomyocyte survival. Trends Cardiovasc Med, 15, 225-9.

Nachtigall PG, Bovolenta LA (2022). Computational Detection of MicroRNA Targets. Methods Mol Biol, 2257, 187-209.

Olive V, Jiang I, He L (2010). mir-17-92, a cluster of miRNAs in the midst of the cancer network. Int J Biochem Cell Biol, 42, 1348-54.

Pawlick JS, Zuzic M, Pasquini G, et al (2021). MiRNA regulatory functions in photoreceptors. Front Cell Dev Biol, 8, doi: 10.3389/fcell.2020.620249.

Pottier C, Fresnais M, Gilon M, et al (2020). Tyrosine kinase inhibitors in cancer: Breakthrough and Challenges of Targeted Therapy. Cancers (Basel), 12.

Schwarzenbach H, Nishida N, Calin GA, et al (2014). Clinical relevance of circulating cell-free microRNAs in cancer. Nat Rev Clin Oncol, 11, 145-56.

Shvartsur A, Givechian KB, Garban H, et al (2017). Overexpression of RKIP and its cross-talk with several regulatory gene products in multiple myeloma. $J$ Exp Clin Cancer Res, 36, 62.

Simanshu DK, Nissley DV, McCormick FJC (2017). RAS proteins and their regulators in human disease. Cell, 170, 17-33.

Sung H, Ferlay J, Siegel RL, et al (2021a). Global Cancer Statistics 2020: GLOBOCAN Estimates of Incidence and Mortality Worldwide for 36 Cancers in 185 Countries. $C A$ Cancer J Clin, 71, 209-49.

Sung H, Ferlay J, Siegel RL, et al (2021b). Global cancer statistics 2020: GLOBOCAN estimates of incidence and mortality worldwide for 36 cancers in 185 countries. $C A$ Cancer J Clin, 2021b.

Swellam M, Mahmoud MS, Hashim M, et al (2019). Clinical aspects of circulating miRNA-335 in breast cancer patients: A prospective study. J Cell Biochem, 120, 8975-82.

Vakkala M, Lähteenmäki K, Raunio H, et al (1999). Apoptosis during breast carcinoma progression. Clin Cancer Res, $\mathbf{5}$, 319-24.

Ventura A, Young AG, Winslow MM, et al (2008). Targeted deletion reveals essential and overlapping functions of the miR-17 through 92 family of miRNA clusters. Cell, 132,
875-86.

Wang F, Zheng Z, Guo J, et al (2010). Correlation and quantitation of microRNA aberrant expression in tissues and sera from patients with breast tumor. Gynecol Oncol, 119, 586-93.

Witwer KW (2015). Circulating microRNA biomarker studies: pitfalls and potential solutions. Clin Chem, 61, 56-63.

Yang G, Zhang R, Chen X, et al (2011). MiR-106a inhibits glioma cell growth by targeting E2F1 independent of p53 status. J Mol Med (Berl), 89, 1037-50.

Yoshikawa M, Iinuma H, Umemoto Y, et al (2018). Exosomeencapsulated microRNA-223-3p as a minimally invasive biomarker for the early detection of invasive breast cancer. Oncol Lett, 15, 9584-92.

You F, Luan H, Sun D, et al (2019). miRNA-106a promotes breast cancer cell proliferation, clonogenicity, migration, and invasion through inhibiting apoptosis and chemosensitivity. DNA Cell Biol, 38, 198-207.

Zhang H, Ge Z, Wang Z, et al (2021). Circular RNA RHOT1 promotes progression and inhibits ferroptosis via mir-106a5p/STAT3 axis in breast cancer. Aging, 13, 8115-26.

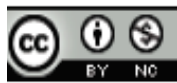

This work is licensed under a Creative Commons AttributionNon Commercial 4.0 International License. 